\title{
Measuring delivery route cost trade-offs between electric-assist cargo bicycles and delivery trucks in dense urban areas
}

\author{
Manali Sheth ${ }^{1 *} \mathbb{D}$, Polina Butrina ${ }^{2 \dagger}$, Anne Goodchild $^{2+}$ and Edward McCormack ${ }^{2+}$
}

\begin{abstract}
Introduction: Completing urban freight deliveries is increasingly a challenge in congested urban areas, particularly when delivery trucks are required to meet time windows. Depending on the route characteristics, Electric Assist (EA) cargo bicycles may serve as an economically viable alternative to delivery trucks. The purpose of this paper is to compare the delivery route cost trade-offs between box delivery trucks and EA cargo bicycles that have the same route and delivery characteristics, and to explore the question, under what conditions do EA cargo bikes perform at a lower cost than typical delivery trucks?
\end{abstract}

Methods: The independent variables, constant variables, and assumptions used for the cost function comparison model were gathered through data collection and a literature review. A delivery route in Seattle was observed and used as the base case; the same route was then modelled using EA cargo bicycles.

Four separate delivery scenarios were modeled to evaluate how the following independent route characteristics would impact delivery route cost - distance between a distribution center (DC) and a neighborhood, number of stops, distance between each stop, and number of parcels per stop.

Results: The analysis shows that three of the four modeled route characteristics affect the cost trade-offs between delivery trucks and EA cargo bikes. EA cargo bikes are more cost effective than delivery trucks for deliveries in close proximity to the DC (less than 2 miles for the observed delivery route with 50 parcels per stop and less than 6 miles for the hypothetical delivery route with 10 parcels per stop) and at which there is a high density of residential units and low delivery volumes per stop.

Conclusion: Delivery trucks are more cost effective for greater distances from the DC and for large volume deliveries to one stop.

Keywords: Electric assist cargo bicycle, Cargo bike, Urban deliveries, Urban logistics, Transportation, Green transportation, Delivery modes, Parcel deliveries, Cargo bicycles, Electric tricycle, E-trike

\section{Introduction}

Understanding the complexity of freight deliveries in dense urban areas is increasingly important. Many cities in the United States are recognizing the impact of urban population growth and e-commerce on freight volumes and the number of freight vehicles on the road. To combat the growing pressures of freight in major urban

\footnotetext{
*Correspondence: manalijs@uw.edu; manalijs@gmail.com

${ }^{\dagger}$ Manali Sheth, Polina Butrina, Anne Goodchild and Edward McCormack contributed equally to this work.

${ }^{1}$ Department of Urban Design and Planning, University of Washington, Box 352700, Seattle, WA 98195, USA

Full list of author information is available at the end of the article
}

areas, cities across the U.S. are responding by deploying alternative transportation modes for delivering goods, such as cargo bikes. It is worthwhile to explore the capabilities of EA cargo bicycles in dense urban areas because it is feasible that this technology could play a role in how cities respond to an increased need for goods movement. The European Cycle Logistics Federation reported that, " $50 \%$ of all light goods, and $25 \%$ of all goods could be moved by cycle" [1]. The capabilities and limitations of EA cargo bikes are poorly understood, and increased knowledge about EA cargo bikes could empower and reform the freight industry. 
The objective of this research is to explore the question, under which route conditions and delivery characteristics do EA cargo bikes perform at a lower cost? This research is motivated by a need to develop a methodological approach that can be replicated and to quantify how bikes may perform in comparison to a standard delivery truck. This question is investigated by capturing route costs associated with each transportation mode in four different delivery scenarios, and by identifying the conditions under which either delivery alternative is preferred with this measurement framework. The findings from this research may be used to support 1) cities when selecting or permitting neighborhoods for cargo bike trials, and 2) carriers when deciding which areas may be most appropriate for cargo bike implementation.

Major metropolitan areas in the U.S. and other parts of the world are facing congestion and environmental issues. The growing number of single occupancy vehicles and truck operations add pressure to transportation networks and infrastructure. Cities are trying to cope with the increased demand for scarce road space by building more transit infrastructure and eliminating parking spaces. Nevertheless, increasing e-commerce activity by city residents drives delivery vehicles to city streets and on-street parking facilities are often unable to accommodate the increased delivery demand. Freight infrastructure in metropolitan areas is unlikely to significantly change to accommodate this increase, and it is important to consider alternative delivery modes. It is clear from traffic congestion, idling trucks, and the lack of sufficient Commercial Vehicle Load Zones (designated freight curb space) that current freight infrastructure is challenged to meet the diverse and dynamic delivery needs of the last mile, which is described as the most costly part of the supply chain in which goods are transported between a DC or warehouse and the recipient's location [2]. To address urban freight delivery challenges, EA cargo bicycles are being utilized for last mile deliveries in several urban cities [3].

Electric Assist (EA) cargo bicycles have been of interest to several major delivery companies as an alternative to trucks for completing urban deliveries. For example, UPS, DHL, and FedEx have been using EA cargo bicycles for almost a decade. A typical EA cargo bicycle has three (a tricycle) or four wheels, a cargo compartment at the back, and a covered console area for the cyclist. They use either pedal power and/or energy from a battery pack. Figure 1 exemplifies two different cargo bike models.

There are some benefits that EA cargo bicycles have, that lend themselves well to the urban environment. Most significant is that EA cargo bicycles are not encumbered by the same parking and congestion constraints as trucks. For example, EA cargo bicycles can use bike lanes as their travel lane and park on sidewalks.
This alternative may help delivery companies reduce their circling and idling time, and deliver items more efficiently. EA cargo bikes may help to make reliable deliveries and may be an effective tool for metropolitan areas to meet environmental targets.

It is important to acknowledge that there are alternative truck types such as electric/hydraulic, electric, propane, and ethanol trucks that are a part of the delivery system [4]. However, regardless of the fuel source, trucks face the same spatial constraints.

In this paper, four urban delivery scenarios completing the same route are modeled using a cost function comparison model, informed by a literature review, interviews, and data collection. Though the base case parameters reflect a case study route in Seattle, Washington, the methodology and findings are applicable to any city confronted by the growing complexities of urban logistics. The cost of using either EA cargo bicycles or urban delivery trucks are quantified and compared while also considering constraints associated with each mode.

\section{Literature review}

Cargo bicycles used for business purposes are a relatively new concept in Europe and the United States, and the need to understand its potential in the delivery ecosystem is critical to its more widespread adoption. Academic papers on the efficacy of cargo bikes in the U.S. and Europe have been reviewed and summarized in the text below and in Table 1.

Choubassi et al. [5] examines and compares the cost of using pedelec bikes - a pedal bike assisted by an electric motor, e-bikes, and e-trikes in three locations with different population densities in Austin, Texas. The e-trike has the lowest cost or net present value amongst all bike types examined, given that there are numerous bike lanes and that there is an urban centric distribution center.

Melo et al. [6] investigates the possibilities of using electric cargo bicycles to move freight in Portugal. Electric cargo bicycles are recognized to have the following advantages over conventional diesel vans: "taxes, insurance, storage, and depreciation costs." They are also easier to park and consume less curb space. In the scenario presented in this research, a maximum of $2 \mathrm{~km}$ was the distance an electric cargo bicycle would travel. Seven scenarios were tested for traffic flow, delay time, average speed, delay times, wheel to wheel energy consumption and $\mathrm{CO} 2$ emissions, and external costs of an electric cargo bicycle using the microscopic traffic simulation model, Advanced Interactive Microscopic Simulator for Urban and Non-Urban Networks (AIMSUN). The researchers concluded that replacing $10 \%$ of delivery vans with electric cargo bicycles would result in reasonable network efficiency and would reduce wheel to wheel Co2 emissions and external costs. 


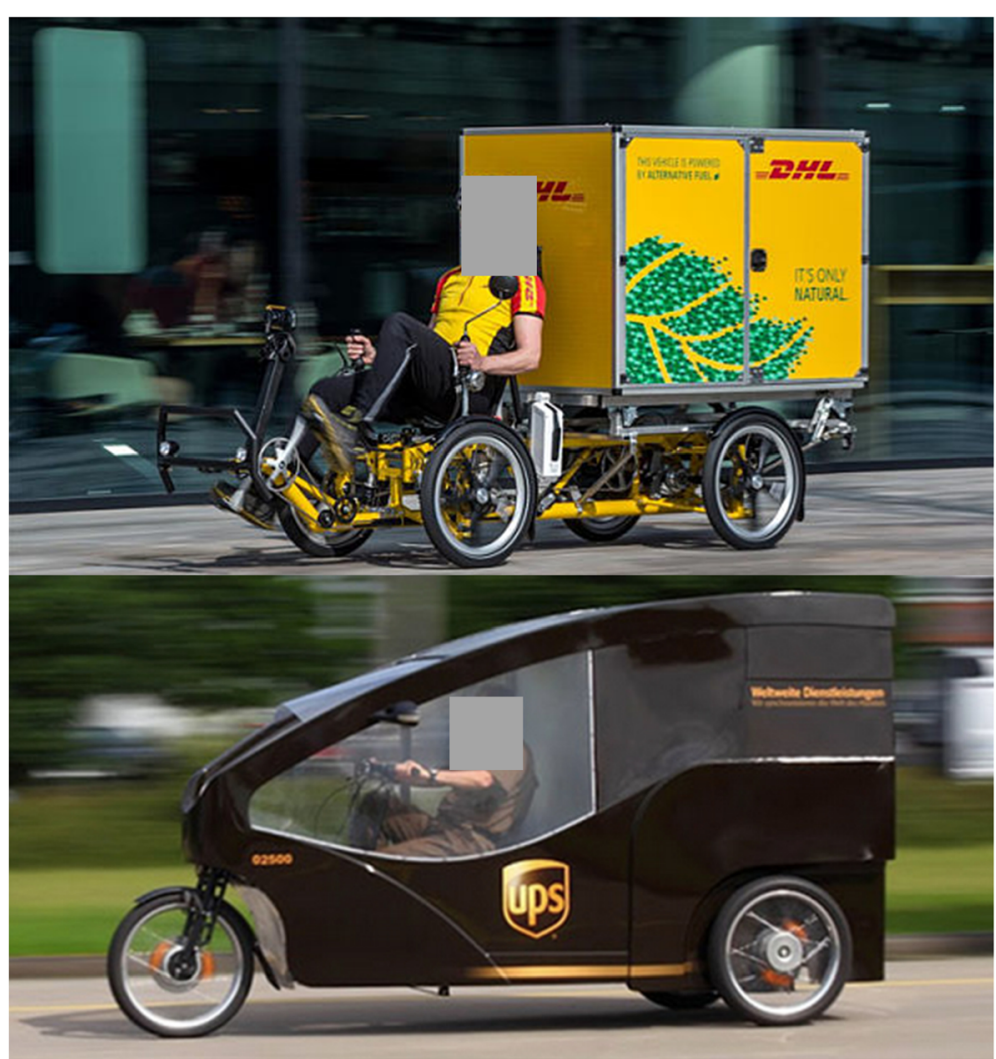

Fig. 1 Two examples of cargo bicycles. DHL (on the left) [18] and UPS (on the right) [19] are using cargo bicycles in their parcel distribution strategies in Europe and the U.S

Tipagornwong et al. [7] used a cost model to compare deploying electric freight tricycles or diesel vans to make deliveries in urban areas. Data from an electric tricycle company in Portland named B-Line, was used to compare costs between an electric freight tricycle and a diesel van going from the distribution center to shops and retail stores (service area), and to ultimately understand the number of each vehicle type required to serve average daily customer demands. Two scenarios are examined; scenario one has a cargo capacity constraint of an average of $50 \mathrm{lbs}$./ parcel, scenario two has a delivery time window constraint of two-to-four hours. The results indicate that for scenario one, using diesel vans is more cost effective than electric freight tricycles by costing $\$ 4000$ less/ work year. For scenario two, freight tricycles are more cost effective, and cost $\$ 9000$ less/ work year than deploying diesel vans. Researchers identify that a change in service time, distance between distribution center and service area, driver unit cost for electric tricycles, and vehicle costs for diesel vans

Table 1 Cargo bicycle literature review summary

\begin{tabular}{|c|c|c|c|c|c|}
\hline Author & Year & City & Country & Research Question & Findings \\
\hline Melo et al. & 2013 & Porto & Portugal & $\begin{array}{l}\text { How can electric cargo cycles impact traffic, } \\
\text { energy efficiency, and emissions in urban } \\
\text { environments? }\end{array}$ & $\begin{array}{l}\text { Replacing } 10 \% \text { of delivery service vans would yield in } \\
\text { better road network efficiency and reduce wheel to wheel } \\
\text { CO2 emissions. and costs. }\end{array}$ \\
\hline $\begin{array}{l}\text { Tipagornwong } \\
\text { et al. }\end{array}$ & 2014 & $\begin{array}{l}\text { Urban } \\
\text { Areas }\end{array}$ & $\begin{array}{l}\text { United } \\
\text { States }\end{array}$ & $\begin{array}{l}\text { How competitive are freight tricycles } \\
\text { compared to diesel vans in terms of costs } \\
\text { and logistical constraints? }\end{array}$ & $\begin{array}{l}\text { Diesel vans are more cost effective for deliveries that } \\
\text { include parcels weighing } 50 \mathrm{lbs} \text {. or more and freight } \\
\text { tricycles are more cost effective for deliveries with time } \\
\text { windows between } 2 \text { and } 4 \mathrm{~h} \text {. }\end{array}$ \\
\hline $\begin{array}{l}\text { Choubassi et } \\
\text { al. }\end{array}$ & 2016 & Austin & $\begin{array}{l}\text { United } \\
\text { States }\end{array}$ & $\begin{array}{l}\text { How do the operating costs compare for } \\
\text { either a pedal bike with an electric motor, } \\
\text { e-bike, or e-trike? }\end{array}$ & An e-trike has the lowest cost of operations. \\
\hline Arnold et al. & 2018 & Antwerp & Belgium & $\begin{array}{l}\text { How can different delivery modes be } \\
\text { compared and assessed for efficacy before } \\
\text { deployment? }\end{array}$ & $\begin{array}{l}\text { Cargo bikes reduce external costs by } 40 \% \text { per delivery. } \\
\text { Driving time increases by } 134 \% \text { with a cargo bike. }\end{array}$ \\
\hline
\end{tabular}


are the most sensitive variables that may greatly change these outcomes.

Arnold et al. [8] simulates and analyzes residential delivery processes in Antwerp, Belgium including scenario using delivery vans (baseline scenario) and alternative scenarios using cargo bicycles and delivery points. The analysis shows that the congestion factor has a minor effect on deliveries performed by delivery vans. Operational and external costs are decreasing with more delivery density. The delivery points showed where customers could pick up deliveries instead of having home deliveries. Delivery point show that fewer number of deliveries must be performed and the number of failed deliveries can be reduced. However, this scenario results in increased traffic and external costs. Simulation of cargo bicycles shows that external costs have decreased by $40 \%$ per delivery when compared with the baseline scenario. The driving time increases by $134 \%$.

As truck emission restrictions have become more stringent, Europe has been the most aggressive in deploying cargo bicycles for deliveries in city centers [9]. European cities typically have narrow streets and older infrastructure as compared to the United States, and bikes are a reasonable solution to road congestion. UPS operates worldwide and has used cities in Europe to experiment with the UPS Cargo Cruiser, an electric assisted tricycle that is ideal for trips to a city center. Major cities where cargo bicycles have been deployed by UPS include Hamburg and Dortmund, Germany; Seattle, Washington, and Portland, Oregon. The bike model used in Hamburg has a cargo compartment that is 77 cubic feet (2.18 cubic meters) and can carry more than 600 lbs. $(272 \mathrm{~kg})$ of cargo.

DHL Express deployed a pilot program in 2017, called City Hub, in Frankfurt, Germany and Utrecht, Netherlands. In this program, a mobile "City Hub," or a group of cargo containers are brought to the city center and attached to custom cargo bicycles. Each bike can carry up to 275 lbs. (125 kg). "Each City Hub can replace up to two standard delivery vehicles, with an equivalent $\mathrm{CO} 2$ saving of over sixteen tons per year and a significant reduction in other emissions" [10]. John Pearson, CEO, DHL Express Europe has noted that "Bicycles...make up to two times as many stops per hour than a delivery vehicle. The total cost of ownership over their lifetime is less than half of a van" [10].

FedEx had a cargo bicycle pilot program in 2009 through their EarthSmart initiative. A small fleet of electric-assist bicycles were deployed in Paris in anticipation of Paris' expansion of its bike lane network. The electric-assist cargo bicycles had a capacity of 53 cubic feet (1.5 cubic meters), operated at $12 \mathrm{mph}(20 \mathrm{~km} /$ hour), and had a range of 25 miles $(40 \mathrm{~km})$ or $6 \mathrm{~h}$. The bikes were an economic and environmental success [11].
One of the biggest competitive advantages a cargo bicycle has over a delivery truck is its ability to spend little time searching for parking. A recent study conducted by INRIX in 2017 indicates that vehicles spend 9 min on average looking for on-street parking and this significantly adds to traffic congestion and emissions. In Los Angeles or New York, it takes 12 and 15 min on average respectively, to look for on-street parking. In Seattle, where this research was conducted, it takes $9 \mathrm{~min}$ on average to find on-street parking. Trucks circling street blocks until parking is found, adds to congestion and increases air pollution. In addition to time spent looking for parking, on street parking require hourly parking payments. In Seattle, two-hour on-street parking costs an average of \$9 [12]. Though this research does not focus specifically on delivery trucks, it serves as a telling proxy for the parking challenges that delivery trucks experience.

Cities need more curb space allocated to support delivery operations. As the competition for curb space grows, so do inadequacies of on-street parking for delivery trucks. For example, the city is removing parking in Downtown Seattle to make room for transportation developments such as bike lanes, light-rail lines, bus lanes, pedestrian pathways and micro parks [13]. New infrastructure added to limited roadways results in the removal or reallocation of parking spots. These developments impact freight efficiency and the delivery process for companies that are already challenged to make their delivery time windows and meet customer expectations.

UPS, FedEx, and other courier companies have commented on the challenges of operating in dense cities and choosing to illegally park and risk receiving a ticket to meet delivery windows [14]. In 2006, UPS spokeswoman Diane Hatcher said, "We receive by far more parking fines in New York City than anywhere else in the world ... Simply stated, we do not have the same level of difficulty with finding available parking spaces or loading zones anywhere else" [14]. Parking tickets are one of the major costs for courier companies. In 2006, couriers large and small, together, owed New York City $\$ 102$ million in parking fines [15]. In the first quarter of 2013, FedEx and UPS owed NYC \$2.8 million total in parking fines [16]. The administrative costs for processing or challenging tickets is immense for both New York City and the courier company. Therefore, New York City cultivated the Stipulated Fine and Commercial Abatement Programs to manage the flow of parking fines associated with delivery trucks [15]. Cargo bicycles do not face the same challenges while operating in a dense urban city because they do not need to park illegally. Table 2 summarizes the advantages and disadvantages of EA cargo bicycles. 
Table 2 Advantages and disadvantages of EA cargo bikes

\begin{tabular}{|c|c|}
\hline Anticipated Advantages of EA Cargo Bikes & Anticipated Disadvantages of EA Cargo Bikes \\
\hline More quiet than an engine due to an electric motor & Higher cost of trans-loading due to smaller cargo capacity \\
\hline $\begin{array}{l}\text { Small enough to maneuver through narrow streets and pedestrian only } \\
\text { zones }\end{array}$ & $\begin{array}{l}\text { Lower economies of scale due to the lower carrying capacity of an EA } \\
\text { cargo bike }\end{array}$ \\
\hline Time saved finding parking because it can park on sidewalks & Limitations in some area due to inability to climb steep slopes \\
\hline $\begin{array}{l}\text { Money saved on parking tickets because it would not be as likely to park } \\
\text { illegally }\end{array}$ & Road regulations (E.g. EA cargo bicycles are illegal in New York City [20]) \\
\hline $\begin{array}{l}\text { Increase in delivery reliability because EA can avoid congested roads and } \\
\text { can use the bike lane to meet delivery deadlines }\end{array}$ & Urban design barriers such as bollards or limited bicycle infrastructure \\
\hline \multirow[t]{2}{*}{$\begin{array}{l}\text { Improved road safety for pedestrians and cyclists as bike collisions are less } \\
\text { severe than collisions with a delivery truck }\end{array}$} & $\begin{array}{l}\text { Other limitations - driver fatigue, depleted battery charge, and extreme } \\
\text { weather conditions (wind, rain, snow, ice, etc.) }\end{array}$ \\
\hline & $\begin{array}{l}\text { Collisions may be more severe for the EA cargo cyclist as compared to } \\
\text { driver in truck }\end{array}$ \\
\hline
\end{tabular}

\subsection{Data collection}

Interviews were conducted with three participants actively involved in the cargo bicycle delivery industry in the Pacific Northwest for insight into real life cargo bike capabilities, limitations, and operations in a city. The interviewees were identified from online research and professional contacts in the freight delivery industry. Each interviewee was contacted via phone or email between January-March 2017, and a series of curated questions were asked to capture information about business operations, cargo bike design and dimensions, and challenges. Knowledge gained from these interviews may be applied to assess the feasibility of cargo bikes in city specific scenarios.

The CEO of Fleetfoot Messenger Service had a contract with an online retailer for a pilot bike delivery program in Seattle that operated between July 2015 and June 2016. The bikes used did not have a cargo compartment, so the volume of goods per delivery were dependent on the physical abilities of the courier themselves. The online retailer did not continue the bike delivery program because it was not a scalable model, since each city the company operates in has its own unique needs and challenges. A former cargo bicycle courier for Freewheel Cargo in Seattle was interviewed to understand the viewpoint of cargo bicycle deliveries from a rider's perspective. To meet delivery deadlines, cyclists would ride on the sidewalk, bike lane, or vehicle lane depending on availability and the traffic. An employee at Truck Trike, a cargo bicycle manufacturing company in Portland, provided information about the dimensions and standards of cargo compartments and the average annual maintenance cost per year. The interviewee noted common cargo bicycle dimensions - rear bed is 81 cubic feet ( 2.3 cubic meters) - 106 cubic feet ( 3 cubic meters) of volume. The annual maintenance cost was about $\$ 340 /$ year. Their electric assist cargo bicycles take 6 to $8 \mathrm{~h}$ to fully charge, and one full charge can last between 12 and 18 miles $(19.3-29 \mathrm{~km})$ dependent on extraneous factors. The battery cost itself is $\$ 1500$ which needs to be replaced after $500+$ charges. These interviews provided costs associated with owning, operating, and maintaining an EA cargo bicycle and were used to develop assumptions and operational costs associated with EA cargo bicycles, which are factored into the four urban delivery scenarios discussed later in the paper.

In addition to the interviews, a large courier company was shadowed for one day to develop a better understanding of a typical truck delivery route in Downtown Seattle. During this process, information about the route and delivery characteristics were collected, and include:

- distance between distribution center (DC) and neighborhood

- number of stops

- distance between stops

- total number of parcels delivered

In ten hours, the delivery truck made eight stops and delivered a total of 400 packages. Delivery stops were on average about 0.2 miles $(0.3 \mathrm{~km})$ from each other. This information became the benchmark for the cost function in which the trade-offs between deliveries via trucks and EA cargo bicycles are examined. Figure 2 is an overview of the delivery route in Downtown Seattle observed during the data collection process. In this image, each red dot is numbered and corresponds to the delivery stop location and number of packages delivered at each location, as shown in the legend. Some stops were visited twice by truck because of a different operation type (package delivery or pickup). For example, Office Tower 2 was visited twice (stops 6 and 9) - at the beginning of the route to deliver parcels and at the end of the route to pick up parcels.

The observed company typically assigns one driver to the same route. The route starts at the DC, which is about 3.5 miles $(5.63 \mathrm{~km})$ from all the delivery stops in downtown Seattle. Before deliveries began, the truck's cargo compartment was at full capacity and held approximately 400 parcels. There are eight delivery stops on 


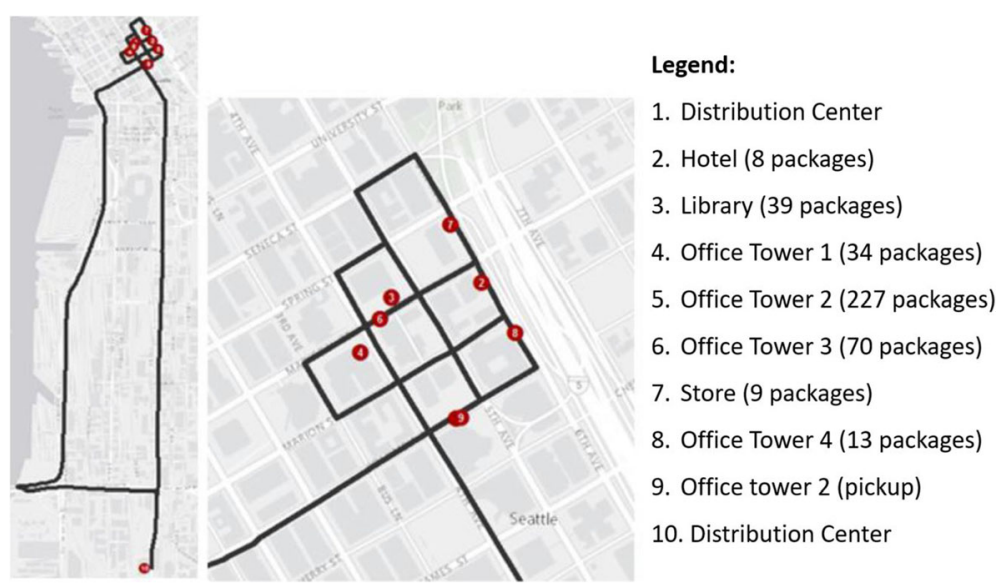

Fig. 2 Map of the observed delivery route. Note: During data collection, some stops were visited twice by the truck for different reasons. The repeated stops are not reflected in the map

this route and they are located about 0.2 miles $(0.3 \mathrm{~km})$ from each other. Even though the stops are quite close to each other, it takes approximately $10 \mathrm{~h}$ to complete all of the deliveries due to tall office towers where the courier had to make deliveries on almost every floor.

The first few deliveries in the route are priority deliveries such as "Air Freight," which must be delivered by 10:30 AM. Then, the driver must deliver "Ground Freight" and pick up outbound parcels at the end of the day. These components reveal the dynamism and considerations a courier company must make when successfully completing a route.

\subsection{Assumptions and cost functions required to model four scenarios}

Four delivery scenarios were modeled to compare the delivery route cost trade-offs between deliveries completed by a delivery truck or EA cargo bicycle. Each scenario manipulates each one of the following independent variables while keeping the other three variables constant.

Independent variables included:

- distance between DC and neighborhood - larger distances impact overall delivery time and costs due to differences in vehicle speeds and driver fatigue (EA cargo bicycle).

- number of stops - the more frequently a vehicle must stop, the more parcels and time spent sorting packages and looking for parking, which impacts overall delivery time and costs.

- distance between stops - larger distances between stops influences the amount of time a vehicle spends in congestion and in transit, which impacts overall delivery time and costs. In dense urban areas, the delivery stops will be concentrated in a small area, so the distance between stops will be small.
- total number of parcels per stop - each vehicle type has its own unique cargo capacity limitations. This influences the number of vehicles required to complete deliveries on any given route and impacts the costs associated with that delivery.

A change in one of these characteristics can influence which mode of transportation is the most cost effective for the last mile. Figure 3 is a diagram of the basic scenario and independent variables examined in this study.

The values given to the constant variables are derived from the research data collection process and are designed to represent a typical urban delivery. The values given for each constant variable are based on the information captured while shadowing the courier company and serves as a proxy for delivery characteristics common to dense cities.

The constant variables are:

- Distance between DC and neighborhood $(\operatorname{Lnb})=3.5$ Miles $(5.63 \mathrm{~km})$

- Number of stops $(N)=8$

- Distance between stops $(L s)=0.2$ miles $(0.3 \mathrm{~km})$

- Number of parcels per stop $(n)=50$

The dependent variable is:

- Route cost (includes driver wages and operational costs)

\section{Assumptions}

Assumptions about the operational characteristics of EA bikes and trucks were developed to ensure consistency while modeling each scenario. These assumptions have been informed by research and interviews, with the intent to produce a good value estimate for each vehicle type.

They are: 


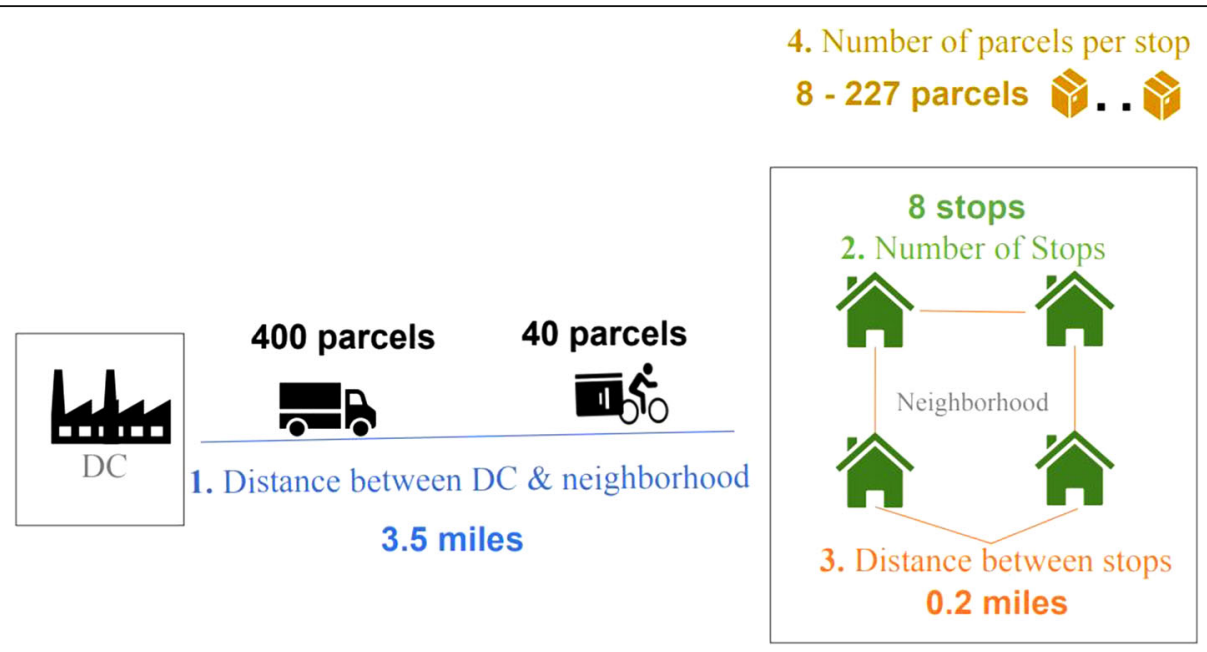

Fig. 3 Diagram of independent variables

- Wages - Truck drivers and EA cargo cyclists are assumed to be paid an average of \$25.17 per hour, and includes hourly wage plus benefits [17].

- Operational Costs - The cost to operate a delivery truck is $\$ 38.53$ per hour [17]. The cost to operate an EA cargo bicycle is $\$ 9.20$ per hour [17]. The following fees are included when calculating operational costs for each model: fuel, truck lease or purchase payments, repair and maintenance, truck insurance premiums, permits and licenses, tires, tolls, driver wages, and driver benefits.

- Delivery Truck Vehicle Characteristics - The courier used a standard box truck, which is common for urban freight deliveries in the United States. The capacity, maximum load, and speed are summarized in Table 3.

- Electric Assist Cargo Bicycle Characteristics The design and dimensions of the cargo bicycle reflects cargo bicycles currently deployed by UPS in Portland, Oregon. It is equipped with brake lights and signal lights, and is therefore suited to use on a roadway, bike lane, or sidewalk. The capacity, maximum load, fuel economy, idling cost, fuel tank capacity and speed are summarized in Table 3.

- Parcel Type - The average parcel size has been computed based on the maximum number of parcels that a transport mode can carry - 400 parcels for a delivery truck and 40 parcels for an EA cargo bicycle.

- Speed - Truck speed is assumed to be 20 miles $(32.2 \mathrm{~km})$ per hour to reflect typical speed limits in dense cities. EA cargo bicycles are assumed to travel at 15 miles $(24.1 \mathrm{~km})$ per hour based on the average speed of a UPS Cargo Cruiser.
- Route Time - For both a truck and EA cargo bicycle, route time is assumed to consist of the distance between the DC and the neighborhood, the distance between each stop, delivery fixed time (includes time looking for parking and parking), and delivery variable time (includes unloading and delivering parcels).

\subsection{Cost function}

The cost function used computes the cost of operating a fleet of EA cargo bicycles that complete the same delivery route as the truck observed during data collection. Cargo capacity and driver working hour constraints were considered for both truck and EA cargo bicycles. Additionally, the EA cargo bicycles have a battery capacity constraint. Accounting for these constraints in the cost function, a range in the number of trucks (one truck could serve the observed delivery route) and EA cargo bicycles required to complete the same route with the same delivery characteristics were found. These values ultimately allow for a direct comparison of route costs between trucks and EA cargo bicycles.

An estimated route cost performed by truck (Eq. 1) is modeled as a sum of cost associated with the driver's

Table 3 Delivery truck and EA cargo bicycle characteristics assumed for modeling

\begin{tabular}{lll}
\hline Metric & Delivery Truck & EA Cargo Bicycle \\
\hline Capacity (cu. ft.) & 865 & 77 \\
Capacity (parcels) & 400 & 40 \\
Maximum load (lbs) & 5930 & 600 \\
Speed (mph) & 20 & 15 \\
Wages (\$) & 25.17 & 25.17 \\
Operational Costs (\$/hour) & 38.53 & 9.2 \\
\hline
\end{tabular}


wage and cost associated with the truck's movements. The equations are shown below and followed by an explanation of notation in Table 4.

$$
f\left(L_{n b}, N, L_{s}, n, n_{v t}\right)=C_{d}+C_{v}
$$

Where

$$
\begin{aligned}
& C_{d}=t_{o} * w \\
& t_{o}=\left(N *\left(t_{f}+t_{v} * n\right)\right)+\frac{d}{v}
\end{aligned}
$$

Equation 2 describes costs associated with the driver. It consists of route time $t_{o}$ multiplied by trucker wage w. Route time (Eq. 3) includes time spent driving to and from the delivery neighborhood, time driving between the stops (assuming that the truck is used to move from one stop to another stop), time spent finding parking, unloading the packages, and making a delivery.

$$
d=n_{v t} *\left(2 * L_{n b}+\frac{L_{s} * n}{n_{v t}}\right)
$$

Equation 4 finds the total route distance $d$ that consists of number of trucks needed to serve the route $n_{v t}$ and the distance between DC and neighborhoods $L_{n b}$, and distance between stops $L_{s}$.

Using the route time and truck operational costs, Equation 5 computes the costs associated with truck usage.

$$
C_{v}=t_{o} * C_{v u}
$$

To find the optimal number of trucks needed to serve the route, capacity restrictions and service time restric-

\begin{tabular}{|c|c|}
\hline$L_{n b}$ & Distance between DC and neighborhood, mi \\
\hline$N$ & Number of stops at the route \\
\hline$L_{s}$ & Distance between stops, mi \\
\hline$n$ & Average number of parcels per stop \\
\hline$n_{v t}$ & Number of trucks needed to serve the route \\
\hline$C_{d}$ & Costs associated with driver, $\$$ \\
\hline$C_{v}$ & Costs associated with vehicle, \$ \\
\hline$C_{v u}$ & Costs of vehicle usage, \$ / hour \\
\hline$t_{f}$ & Delivery fixed time (equal to $0.15 \mathrm{~h}$ [14] for trucks and $0.06 \mathrm{~h}$ for bicycles), $\mathrm{h}$ \\
\hline$t_{o}$ & Total route time traveled by all vehicles, $\mathrm{h}$ \\
\hline$t_{v}$ & Delivery variable time (equal to $0.008 \mathrm{~h}$ for both trucks and bicycles), $\mathrm{h} /$ parcel \\
\hline$d$ & Total route distance, mi \\
\hline$v$ & Vehicle traveling speed, mi/h \\
\hline$w$ & Driver wage, $\$ / \mathrm{h}$ \\
\hline$n_{v b}$ & Number of bikes needed to serve the route \\
\hline$n_{v t_{c a p}}$ & Number of trucks needed to serve the route with capacity restrictions \\
\hline$n_{v t_{T}}$ & Number of trucks needed to serve the route with driver working hours restrictions \\
\hline$p_{\text {dim }}$ & Average package dimension, $\mathrm{ft}^{3}$ (equal to $1.96 \mathrm{ft}^{3}$ ) \\
\hline$t_{\text {cap }}$ & Truck capacity, $\mathrm{ft}^{3}$ \\
\hline$t_{\text {travel }}$ & Route travel time, $\mathrm{h}$ \\
\hline$t_{\text {deliv }}$ & Route delivery time, $\mathrm{h}$ \\
\hline$t_{w d}$ & Driver working day time, $\mathrm{h}$ (equal to $10 \mathrm{~h}$ ) \\
\hline$b_{\text {cap }}$ & EA cargo bicycle capacity, $\mathrm{ft}^{3}$ \\
\hline$d_{b}$ & An average maximum distance EA cargo bike can travel, mi (equal to 18 miles) \\
\hline$n_{v b}^{c a p}$ & Number of bicycles needed to serve the route with capacity restrictions \\
\hline$n_{v b_{T}}$ & Number of bicycles needed to serve the route with driver working hours restrictions \\
\hline$n_{v b_{b}}$ & Number of bicycles needed to serve the route with the battery restrictions \\
\hline
\end{tabular}
tions are applied. Equations 8 and 9 compute the number of trucks needed to serve the route under the restrictions mentioned.

Table 4 Notation for the cost function 


$$
n_{v t}=\max \left(n_{v t_{c a p}}, n_{v t_{T}}\right)
$$

Where

$$
\begin{aligned}
& n_{v t_{\text {cap }}}=\frac{\left(p_{\text {dim }} * n * N\right)}{t_{\text {cap }}} \\
& n_{v t_{T}}=\frac{t_{\text {travel }}+t_{\text {deliv }}}{t_{w d}}
\end{aligned}
$$

Where

$$
\begin{aligned}
t_{\text {travel }} & =\frac{d}{v} \\
t_{\text {deliv }} & =N *\left(t_{f}+t_{v} * n\right)
\end{aligned}
$$

Equation 8 uses truck capacity and an average parcel size for the route. It was observed that delivery box truck could fit approximately 400 parcels and an estimation of average parcel size was assumed to be $1.96 \mathrm{ft}^{3}$.

Delivery route time (Equations 9) consists of truck travel time (Equation 10) and package delivery time (Equation 11).

After, Equation 7 finds the minimum number of trucks to make deliveries under the capacity and service time restrictions (using less trucks would not fit the parcels or would run out of service time).

Bicycle Operating Costs (Equation 12) include costs associated with freight bicycle operator (Equation 2) and freight bicycle operation costs (Equation 5).

$$
f\left(L_{n b}, N, L_{s}, n, n_{v b}\right)=C_{d}+C_{v}
$$

The same restrictions as for number of trucks that need to serve the route apply to the freight bicycles (Equations 14 and 15). In addition, battery restrictions were applied for the bike, assuming EA freight bicycle's battery will last for 18 miles (Equation 16).

$$
n_{v b}=\max \left(n_{v b}^{c a p}, n_{v b_{T}}, n_{v b_{b}}\right)
$$

Where

$$
\begin{aligned}
& n_{v b}^{c a p}=\frac{\left(p_{\text {dim }} * n * N\right)}{b_{\text {cap }}} \\
& n_{v b_{T}}=\frac{t_{\text {travel }}+t_{\text {deliv }}}{t_{w d}} \\
& n_{v b_{b}}=\frac{2 * L_{n b}+L_{s} * N}{d_{b}}
\end{aligned}
$$

Equation 13 finds the minimum number of vehicles required to make deliveries under the constrains mentioned above (using less EA freight bicycles would not fit the parcels, or run out of charge, or run out of service time).

\section{Results of modeling four scenarios}

The cost function is applied to compare the route cost for trucks and EA cargo bikes by changing one of the four independent route variables for both transportation modes. Each scenario has been modeled to depict how route costs between an urban delivery truck and an EA cargo bicycle compare to one another when changing delivery route characteristics. The characteristics of the observed route have been modeled and can be seen in Fig. 4.

In scenario $4 \mathrm{a}$, both transportation modes have eight stops in the route, a distance of 0.2 miles between each stop, and deliver 50 parcels per stop. In this scenario, the distance between the DC and delivery neighborhood is modeled from 0 to 10 miles $(16.1 \mathrm{~km})$. This shows that where the distance between DC and delivery neighborhood was greater than 2 miles $(3.2 \mathrm{~km})$, it was more cost efficient to use a delivery truck in comparison to EA cargo bikes. If the DC were to be located closer to the delivery neighborhood, at least less than 2 miles $(3.2 \mathrm{~km})$ away, it would be slightly more cost effective to use EA cargo bikes on the route observed.

In scenario $4 \mathrm{~b}$, both transportation modes have eight stops in the route, deliver 50 parcels per stop, and have a distance of 3.5 miles between the DC and neighborhood. In this scenario, the distance between delivery stops is modeled from 0 to 1 mile $(1.6 \mathrm{~km})$, assuming that anything beyond 1 mile $(1.6 \mathrm{~km})$ indicates deliveries are occurring in less dense urban areas, which is outside the scope of this study. Figure $4 \mathrm{~b}$ shows that the cost lines for both vehicle types are almost constant. This could be because the distance between each stop is very small in urban areas due to more frequent delivery stops, and therefore has little impact on overall route costs. The truck is more cost efficient than EA cargo bicycles at any distance between stops in the observed delivery route.

In scenario $4 \mathrm{c}$, both transportation modes have eight stops in the route, have a distance of 3.5 miles between the DC and neighborhood, and a distance of 0.2 miles per stop. In this scenario, the number of parcels was modeled from 1 to 70 parcels per stop. Adding 5 parcels per stop increases the number of EA cargo bicycle trips required due to capacity limitations. Additionally, each package increases handling time at the stop, slightly increasing total route costs. The truck cost line is also gradually increasing as the number of parcels increases, but has a smaller slope in comparison to an EA cargo bicycle. There is a significant increase in truck costs when the total number of packages exceeds the truck's 400 parcel capacity. For the observed route, if there were more than 25 parcels per stop on average, it would be more cost efficient to use a truck instead of an EA cargo bicycle because otherwise, two or more EA cargo 


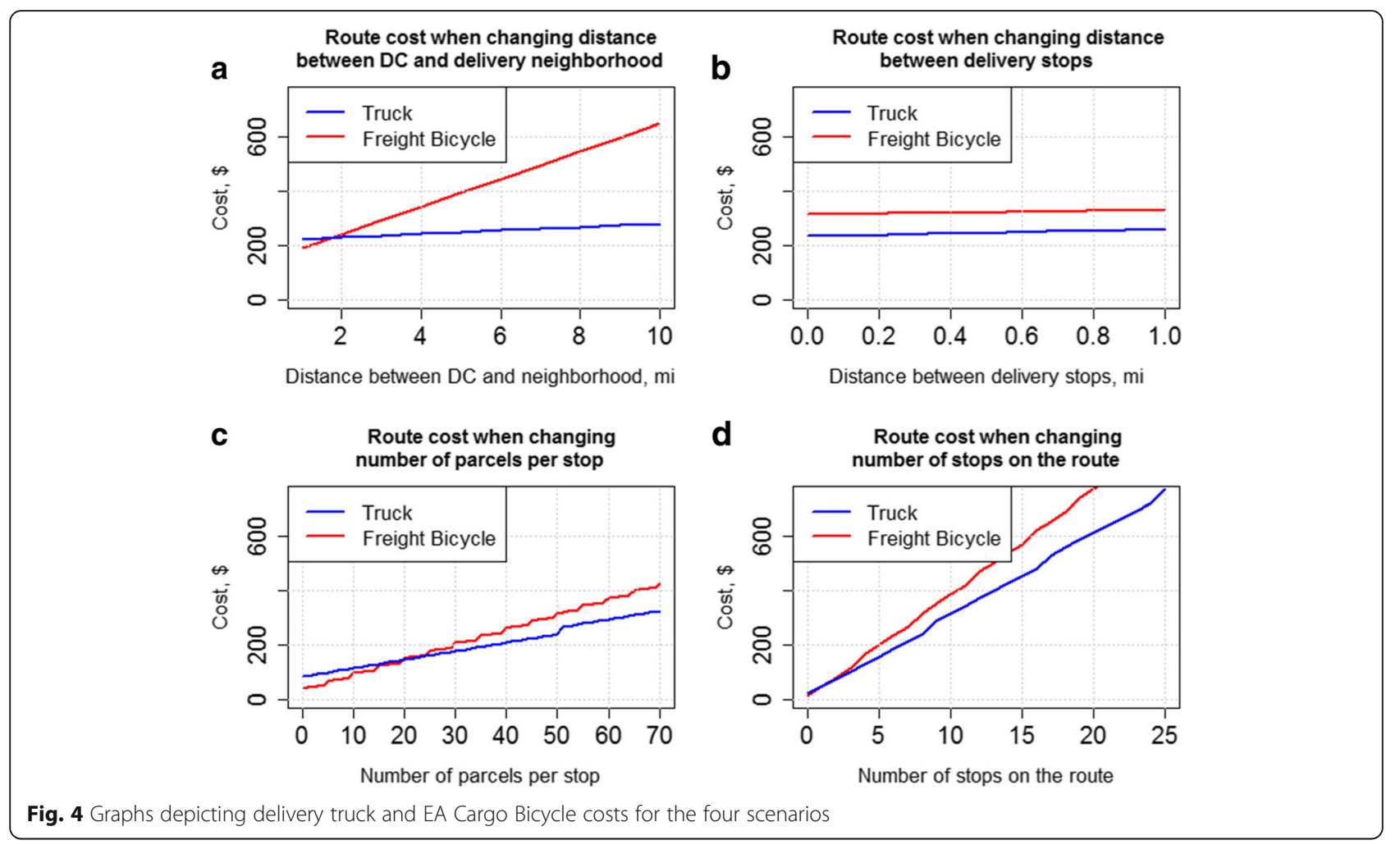

bicycles would be required to serve the same number of stops. If the number of parcels per stop is less than 20 parcels, it would be most cost efficient to use an EA cargo bicycle for the route.

In Fig. 4d, both transportation modes have a distance of 3.5 miles between the DC an neighborhood, a distance of 0.2 miles between each stop, and deliver 50 parcels per stop. In this scenario, the number of stops on the route was modeled from 0 to 25 stops. This graph shows that if the route has three or fewer stops on the route, the cost for EA cargo bicycles and trucks will be the same. If the route has more stops, it is more cost efficient to use a delivery truck instead of an EA cargo bicycle.

Based on modeling results, EA cargo bicycles are not the most cost-efficient vehicle type for the observed route. This is mainly due to the cargo capacity restrictions associated with the EA cargo bicycle. The average number of parcels per stop was 50 parcels, which surpasses the capacity of a single EA cargo bicycle which is 40 parcels. Therefore, at least 2 cargo bicycles would have to be allocated to each stop. It would take $10 \mathrm{EA}$ cargo bicycles to replace a single delivery truck completing the observed route.

Findings from Fig. 4 indicate that a decrease from 50 parcels per stop to 10 parcels per stop would make an EA cargo bicycle more cost efficient than a delivery truck. Therefore, to further examine the feasibility of EA cargo bicycles, four scenarios were modeled using the same cost function, dependent variables, and assumptions, but one of the four independent variable values was changed. Instead of having 50 parcels per stop, this scenario will have 10 parcels per stop. The total number of parcels have changed from 400 parcels per route to 80 parcels per route. The results of this analysis can be seen in Fig. 5.

In scenario $5 \mathrm{a}$, both transportation modes have eight stops in the route, a distance of 0.2 miles between each stop, and deliver ten parcels per stop. In this scenario, the distance between the DC and delivery neighborhood is modeled from 0 to 10 miles $(16.1 \mathrm{~km})$. The route cost is more cost effective using EA cargo bikes for up to 6 miles $(9.7 \mathrm{~km})$ between the DC and neighborhood. Beyond a 6 -mile $(9.7 \mathrm{~km})$ distance, delivery trucks are more cost effective for this scenario.

In scenario $5 \mathrm{~b}$, both transportation modes have eight stops in the route, deliver ten parcels per stop, and have a distance of 3.5 miles between the DC and neighborhood. In this scenario, the distance between each of the eight delivery stops is examined from 0 to 1 mile (1.6 $\mathrm{km})$. Regardless of the distance between each stop, EA cargo bikes are more cost effective for at least up to 1 mile $(1.6 \mathrm{~km})$ between stops.

The outcome of scenario $5 \mathrm{c}$ is exactly the same as scenario $4 \mathrm{c}$ because all of the values applied to the cost function are the same. 
In scenario $5 \mathrm{~d}$, both transportation modes have a distance of 3.5 miles between the DC and neighborhood, 0.2 miles between each stop, and deliver ten parcels per stop. This scenario compares the cost of EA cargo bikes and a delivery truck when the number of stops on the route changes from 0 to 25 stops. According to this scenario, EA cargo bikes are more cost effective for at least 25 stops in the given route.

By changing the variable for the number of parcels delivered at each stop from 50 to 10, EA cargo bicycles are generally more cost effective than urban delivery trucks. It can be concluded that it is more cost efficient to deliver a smaller number of parcels to more stops by EA cargo bicycles.

\section{Conclusion}

The literature review and interviews indicate that EA cargo bicycles have piqued the interest of the private and public delivery sectors. Though there are limitations associated with EA cargo bicycles, delivery companies and universities are exploring improvements in the design and utility of EA cargo bicycles in urban areas.

The four scenarios modelled in this paper indicate that cargo bikes are more cost effective than delivery trucks for deliveries in close proximity to the distribution center (less than 2 miles for the observed delivery route with 50 parcels per stop and less than 6 miles for the hypothetical delivery route with 10 parcels per stop) and at which there is a high density of residential units and low delivery volumes.

Delivery trucks are more cost effective for greater distances from the DC and for large volume deliveries to one stop. For example, the observed route had a large volume of deliveries to one major office tower. Due to the truck's large carrying capacity, the route could be completed by one truck, instead of deploying at least ten EA freight bicycles to complete the same delivery. Moreover, by delivering greater number of packages per stop to office towers or any high-rise building with designated loading docks, trucks are able to legally park for longer periods of time. Therefore, EA cargo bikes may be well suited for congested cities with designated bike paths and truck parking challenges.

Cities and deliveries are increasingly becoming more populated, dense and dynamic, and it is important to acknowledge that though EA cargo bicycles have the potential to optimize specific nodes of the supply chain, they certainly are not a one size fits all solution for urban freight. For example, it was observed during data collection that "Air Freight" was the most time sensitive delivery type with a smaller number of "Air Freight" packages per stop. Thus, it is possible that EA cargo bicycles can be allocated to effectively deliver these types of packages. Having DCs closer to the city center may also support EA cargo bicycles as the optimal delivery

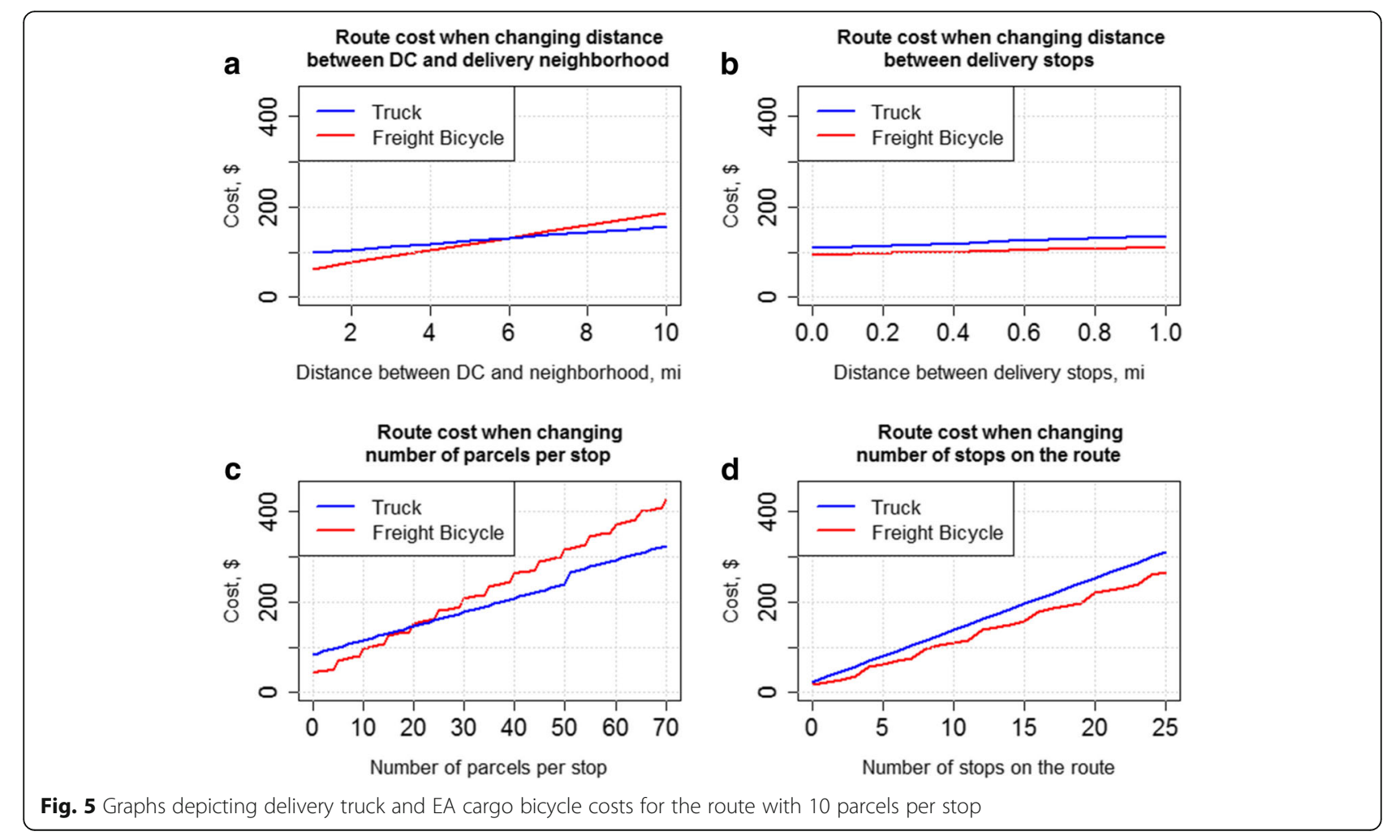


transportation mode type for priority shipments such as one or two-hour deliveries.

EA cargo bicycles have some competitive advantages over delivery trucks in that cargo bicycles have more options for maneuvering through a city using the road, bike lane, sidewalks, and accessing pedestrian only areas, so a more detailed modeling of those aspects is warranted. The time spent looking for parking and the act of parking the bike itself is minimal.

Cargo bicycles may be a good substitute for trucks in cities that are considering policies that restrict the time and type of freight trucks driving through cities using congestion charges or simply banning them. Another possibility is to incentivize the use of cargo bicycles by including city support for bike storage in or near downtown. Cargo bicycles could also be a mode of transit included and discussed in city master plans.

The growing number of cargo bicycle companies in the United States and research efforts are certainly promising. The intent of this research is to contribute to the understanding of EA cargo bicycles and their potential to carry freight in urban environments. Seattle has been used as the case study, but the results can be applied to other urban cities in the United States.

\section{Acknowledgements}

Not Applicable.

\section{Funding}

Not Applicable.

\section{Availability of data and materials}

This manuscript is based off of data obtained during observations, literature review, and interviews.

\section{Authors' contributions}

MS,PB,AG,EM contributed equally to the development of this manuscript. All authors read and approved thr final manuscript.

\section{Competing interests}

There are no competing interests in the making and publishing of this manuscript.

\section{Publisher's Note}

Springer Nature remains neutral with regard to jurisdictional claims in published maps and institutional affiliations.

\section{Author details \\ 'Department of Urban Design and Planning, University of Washington, Box 352700, Seattle, WA 98195, USA. ${ }^{2}$ Department of Civil and Environmental Engineering, University of Washington, Box 352700, Seattle, WA 98195, USA.}

Received: 8 June 2018 Accepted: 16 January 2019

Published online: 13 February 2019

\section{References}

1. Auchapt, Diane. "cargo bicycle crazy: The potential of delivering goods by bike." ECF. European Cyclists' Federation, 4 Dec. 2012 Web 262017.

2. Wang, Y., Jiang, X., Lee, L. H., Chew, E. P., \& Tan, K. C. (2017). Tree based searching approaches for integrated vehicle dispatching and container allocation in a transshipment hub. Expert Syst Appl, 74.
3. "European Cycle Logistics Federation Conference 2014." European Cycle Logistics Federation Conference 2014 | Cyclelogistics Federation. N.p., 01 Jan. 1970. Web. 30 July2017. http://eclf.bike/about.html.

4. UPS, ed. "Environmental Responsibility." UPS Rolling Laboratory (n.d.): n. pag 2016. Web. https://sustainability.ups.com/media/UPS_Rolling_Lab.pdf.

5. Choubassi, C., Seedah, D. P. K., Jiang, N., \& Walton, C. M. (2016). Economic Analysis of Cargo Cycles for Urban Mail Delivery Transportation Research Record. J Transportation Res Board, 2547, 102-110.

6. Melo, S., Baptista, P., \& Costa, Á. (2014). Comparing the use of small sized electric vehicles with diesel vans on city logistics. Procedia Soc Behav Sci, $111,350-359$

7. Tipagornwong, C., \& Figliozzi, M. (2014). Analysis of competitiveness of freight tricycle delivery Services in Urban Areas. Transportation Research Record: Journal of the Transportation Research Board, 2410, 76-84.

8. F. Arnold, I. Cardenas, K. Sörensen, W. Dewulf, (2018) Simulation of B2C ecommerce distribution in Antwerp using cargo bikes and delivery points. European Transport Research Review 10 (1).

9. DeDecker, Kris. "Cargo Cyclists Replace Truck Drivers on European City Streets." Low-Tech Magazine. N.p.n.d. Web. 24 Sept 2012

10. Bonn. "Press Release." DHL Expands Green Urban Delivery with City Hub for Cargo Bicycles. DHL Express, 2017. Web. 30 Jul 2017. http://www.dhl.com/ en/press/releases/releases_2017/all/express/dhl_expands_green_urban_ delivery_with_city_hub_for_cargo_bicycles.html.

11. "FedEx Express and Urban-Cab Join Forces for Ecological Deliveries." About FedEx. FedEx, 2009. Web. 19 Jul 2017. https://about.van.fedex.com/ newsroom/fedex-express-and-urban-cab-join-forces-for-ecologicaldeliveries/.

12. INRIX. "The Impact of Parking Pain in the US, UK, and Germany."Web. 19 July 2017. https://www.documentcloud.org/documents/3892952-INRIXParking-ResearchFINAL-Low-Res.html.

13. Byron, Linda. "Is Seattle Waging a War on Cars?" K5. N.p., 2015. Web. 30 Jul 2017. http://www.king5.com/news/is-seattle-waging-a-war-on-cars/ 157490616.

14. Goldman, Adam. "Delivery Vans Get Steep Fines in NYC." The Associated Press. N.p., 2006. Web. 30 Jul 2017. http://www.washingtonpost.com/wpdyn/content/article/2006/09/01/AR2006090100863_pf.html.

15. Ganninger, Daniel. "Upset Over a Parking Ticket? Wait Until You See What FedEx and UPS Have to Pay." Knowledge Stew. N.p., n.d. Web. 30 Jul 2017. https://knowledgestew.com/2015/09/parking-tickets-fedex-ups.html.

16. Calder, Rich. "FedEx, UPS Owe $\$ 2.8$ Million in Parking Tickets to City in First Three Months of 2013." New York Post. New York Post, 2013. Web. 30 Jul 2017. https://nypost.com/2013/05/27/fedex-ups-owe-2-8-million-in-parkingtickets-to-city-in-first-three-months-of-2013/.

17. "An Analysis of the Operational Costs of Trucking: 2016 Update." American Transportation Research Institute (2016): 1-41. Print.

18. DHL. http://www.dhl.com/en/press/releases/releases_2017/all/express/dhl expands_green_urban_delivery_with_city_hub_for_cargo_bicycles.html. Accessed 15 May 2018.

19. UPS. http://ichef.bbci.co.uk/wwfeatures/wm/live/1280_640/images/live/p0/ 24/vq/p024vqg6.jpg/. Accessed 15 May 2018.

20. Vicky, Gan. "The Murky Legality of E-Bikes" CityLab, 2016. https://www. citylab.com/equity/2016/02/the-murky-legality-of-e-bikes/426969/.

\section{Submit your manuscript to a SpringerOpen ${ }^{\circ}$ journal and benefit from:}

- Convenient online submission

- Rigorous peer review

- Open access: articles freely available online

- High visibility within the field

- Retaining the copyright to your article

Submit your next manuscript at $\boldsymbol{\nabla}$ springeropen.com 